\title{
Habitat use and distribution of the Beautiful Firetail (Stagonopleura bella) in foothill forests of the Victorian Highlands, Australia
}

\author{
Grant C. Palmer \\ Landscape Ecology Research Group, School of Ecology and Environment, \\ Deakin University, 221 Burwood Hwy, Burwood, Vic. 3125, Australia. \\ Present address: Centre for Environmental Management, School of Science and Engineering, \\ University of Ballarat, PO Box 663, Ballarat, Vic. 3353, Australia. Email: g.palmer@ballarat.edu.au
}

\begin{abstract}
The Beautiful Firetail (Stagonopleura bella) is an uncommon, granivorous finch from coastal south-eastern Australia, with a distribution extending from mid-coastal New South Wales to south-eastern South Australia, including Tasmania. This paper presents a quantitative assessment of habitat use by the Beautiful Firetail based on data collected from 30 paired riparian and non-riparian sites in the foothill forests of the Victorian Highlands, Australia. The Beautiful Firetail occurred in two of the three forest blocks surveyed and was found almost exclusively at riparian sites. The Beautiful Firetail was most likely to occur at riparian sites on the coastal fall of the ranges at sites with high sedge cover and low cover of shrubs and bare ground. The species occurred at low densities (0.10-0.19 individuals $\left.\mathrm{ha}^{-1}\right)$ throughout the year. Records from the Atlas of Victorian Wildlife were used to describe the distribution of Beautiful Firetails in Victoria. Notable observations inland of the Great Dividing Range were recorded during the present study. Further study is required to understand the ecological requirements of the Beautiful Firetail throughout its range.
\end{abstract}

\section{Introduction}

The Beautiful Firetail (Stagonopleura bella) is one of three firetail finches (genus Stagonopleura), all of which are endemic to Australia. It is granivorous and has a restricted distribution along the coast of south-eastern Australia, ranging from Newcastle on the central coast of New South Wales, to the Mt Lofty Ranges in South Australia (Blakers et al. 1984; Barrett et al. 2003). It is the only species of native finch to inhabit Tasmania, where it is considered common (Immelmann 1965; Blakers et al. 1984). There are several gaps in its range, isolating several distinct populations (Blakers et al. 1984; Schodde and Mason 1999). In Victoria, Emison et al. (1987) reported 159 records of the species, concentrated in coastal areas. It was not recorded inland of the Great Dividing Range (Emison et al. 1987) and although it has been reported from the Lake Eildon and Mt Beauty areas (Pizzey 1980), such records are unconfirmed (Blakers et al. 1984). Notable population declines of this species have occurred in the western extent of its range (SAOA 1977; Barrett et al. 2003). Recent atlas data have shown that the reporting rate of the Beautiful Firetail decreased by $>20 \%$ in parts of its range over the last two decades, particularly at the western and northern extremities (Blakers et al. 1984; Barrett et al. 2003).

Schodde and Mason (1999) recognise three ultrataxa for the species, each of which is largely isolated from the others.
There are significant biogeographical barriers that fragment the distribution of the species. The semi-arid environment surrounding the mouth of the Murray River, South Australia, isolates $S$. bella samueli at the western extent of the species' distribution around the Mt Lofty Ranges and Kangaroo Island. Similarly, the coastal intrusion of the grassland-dominated Victorian Volcanic Plain bioregion around Warrnambool and Portland isolates the ultrataxon S. b. interposita - occurring east of the Murray River mouth in (SA) to west of Portland (Vic.) - from the most widespread form, S. b. bella, which occurs east of Warrnambool and into southern New South Wales. This ultrataxon also occurs in Tasmania, where it is separated from the mainland by Bass Strait.

The Beautiful Firetail is primarily considered a species of coastal habitats, being closely associated with coastal heaths and tea-tree scrubs (Immelmann 1965; Emison et al. 1987; Read 1987; Wood 1998). It also frequents heathy woodlands and wet forest gullies away from the coast, including regrowth forest following timber harvesting (Loyn et al. 1980; Emison et al. 1987; Joint Scientific Committee 1990). There has been little research on the ecological requirements of the Beautiful Firetail and its habitat preferences are poorly understood.

In this paper, I first outline known distribution of the Beautiful Firetail in Victoria, based on records from the Atlas of Victorian Wildlife (Department of Sustainability and 
Environment). Then, within this geographical context, I describe the distribution and habitat use of Beautiful Firetails at a series of riparian and non-riparian sites in a forest mosaic in southern Victoria. Descriptive observations of other aspects of the species' ecology are also presented.

\section{Methods}

Study area

The study was conducted in three large, continuous forest blocks in the foothills of the Victorian Highlands, south-eastern Australia: Bunyip State Park $\left(37^{\circ} 56^{\prime} \mathrm{S}, 145^{\circ} 35^{\prime} \mathrm{E}\right)$, Kinglake National Park $\left(37^{\circ} 29^{\prime} \mathrm{S}\right.$, $\left.145^{\circ} 22^{\prime} \mathrm{E}\right)$ and Marysville State Forest $\left(37^{\circ} 34^{\prime} \mathrm{S}, 145^{\circ} 41^{\prime} \mathrm{E}\right)$. This region comprises an extensive forest mosaic and is characterised by mixed Eucalyptus species forests flanking the Great Dividing Range.

\section{Study sites}

Sites were selected as part of a broader study investigating the importance of riparian zones to bird assemblages in forest mosaics. Based on five stream systems in the forest mosaic, a series of 30 paired riparian and adjacent non-riparian sites (20 site-pairs in Bunyip State Park, five in Kinglake National Park, and five in Marysville State Forest) were investigated. Twenty site-pairs were located on the coastal fall of the Great Dividing Range (Bunyip State Park) and ten were located on the inland fall (Kinglake National Park and Marysville State Forest).

Riparian sites were confined to riparian forest ecological vegetation class and were positioned immediately adjacent to the streams, the inner boundary being $\sim 5 \mathrm{~m}$ from the water channel. Non-riparian sites were on adjacent slopes, $\sim 750 \mathrm{~m}$ from their riparian partners. Non-riparian sites occurred in several ecological vegetation classes, ranging from wet forest to lowland forest and heathy woodland.

\section{Habitat assessments}

Habitat measurements based on a life-form structural assessment were conducted at each site during spring 2002. Tree measurements were gathered within a randomly placed $0.25 \mathrm{ha}(100 \mathrm{~m} \times 25 \mathrm{~m})$ quadrat at each site. All trees were counted and determined to be either canopy or midstorey forms. The diameter-at-breast-height (dbh) of each tree was measured and counts recorded of trees $<10 \mathrm{~cm}$ dbh (Table 1). Visual estimates were made of the cover (\%) of the canopy. For shrub assessments, a randomly placed $625 \mathrm{~m}^{2}(25 \mathrm{~m} \times 25 \mathrm{~m})$ quadrat was used at each site.
Within this quadrat, shrubs were counted and assigned to one of two height-classes: tall shrubs (shrubs $>2 \mathrm{~m}$ ) and low shrubs (shrubs $<2 \mathrm{~m}$ ) (Table 1). The cover (\%) of each height class was visually estimated. The cover $(\%)$ of a suite of vegetation life forms - low ferns, grasses and sedges - was also measured within this quadrat (Table 1). The cover abundance (\%) of bare ground and fine litter was assessed in four $25 \mathrm{~m}^{2}$ $(5 \mathrm{~m} \times 5 \mathrm{~m})$ quadrats and average values generated for each site.

\section{Bird surveys}

Bird surveys were carried out at each site at a rate of five visits per season (i.e. one or two visits per month) between July 2001 and December 2002 (total $=29$ visits). Surveys were conducted using a fixed-point count method (Pyke and Recher 1984). At each site, fixedpoints were centrally located in two adjoining $50 \mathrm{~m} \times 50 \mathrm{~m}$ plots, which yielded a combined sampling area of 0.5 ha. Consecutive 8-min counts were conducted at each point, in which all birds seen and heard were recorded, including those outside of plots. For visual observations of individual birds, the following positional and foraging data were collected: habitat structural feature, substrate, food item, behaviour, plant species and vertical position. Observations of breeding and other notable behaviour were also recorded. Bird surveys were conducted throughout the day (between sunrise and sunset) in suitably still and dry conditions. The sequence in which paired sites were visited was randomised for each stream system.

\section{Analysis}

The set of geographical, landscape and habitat variables was initially analysed using a univariate approach to assess their effect on the response variable, the presence of Beautiful Firetails. A correlation matrix between the predictor variables was used to assess collinearity levels. Owing to strong collinearity between several predictors, ecologically related variables - the low vegetation and ground cover variables - were transformed (using arcsine transformations to meet assumptions of normality), converted to a Bray-Curtis similarity matrix and analysed using MDS ordination (PRIMER; Clarke and Gorley 2001). This method was used to reduce ecologically related variables to a smaller set of predictor variables (MDS axes) representing low vegetation and ground cover.

Logistic regression was used to estimate the probability of the occurrence of Beautiful Firetails at a site as a function of geographical and habitat variables. The dependent variable was the presence or

Table 1. Univariate analyses of the relationship between the presence of Beautiful Firetails and environmental variables at sites

Mean values of variables are presented for sites where the Beautiful Firetail was present or absent during the study. Significant variables are indicated in bold. Comparisons were made using either $\chi^{2}$ tests or Student's $t$-tests, as shown in parentheses for each variable

\begin{tabular}{|c|c|c|c|c|}
\hline Environmental variable & Present & Absent & Statistic & $P$ \\
\hline Geographical location $\left(\chi^{2}\right.$, d.f $\left.=3\right)$ & - & - & 12.25 & $<0.001$ \\
\hline Landscape position $\left(\chi^{2}\right.$, d.f. $\left.=3\right)$ & - & - & -19.82 & $<0.001$ \\
\hline No. small trees ha ${ }^{-1}(t$, d.f. $=58)$ & 261.4 & 169.9 & 3.889 & 0.083 \\
\hline Coarse woody debris $(t$, d.f. $=58)$ & 1.4 & 1.7 & -0.701 & 0.486 \\
\hline \multicolumn{5}{|l|}{$\%$ cover of: } \\
\hline Canopy $\left._{(t, \text { d.f. }}=58\right)$ & 37 & 52 & -3.505 & 0.001 \\
\hline Tall shrub $\left._{(t, \text { d.f. }}=58\right)$ & 17 & 24 & -2.118 & 0.036 \\
\hline Low $\left.\operatorname{shrub}_{(t, \text { d.f. }}=58\right)$ & 6 & 19 & -4.198 & $<0.001$ \\
\hline $\left.\operatorname{Fern}_{(t, \text { d.f. }}=58\right)$ & 29 & 25 & 0.704 & 0.484 \\
\hline Sedge $\left._{(t, \text { d.f. }}=58\right)$ & 42 & 14 & 5.803 & $<0.001$ \\
\hline $\left.\operatorname{Grass}_{(t, \text { d.f. }}=58\right)$ & 25 & 37 & -1.312 & 0.171 \\
\hline Fine litter $(t$, d.f. $=58)$ & 36 & 50 & -2.472 & 0.016 \\
\hline Bare ground $(t$, d.f. $=58)$ & 10 & 13 & -0.767 & 0.446 \\
\hline
\end{tabular}


absence of Beautiful Firetails at a site, pooled for the 29 visits. Predictor variables included geographical position (coastal or inland), canopy cover, number of small trees, tall shrub cover and two ordination dimensions, MDS1 and MDS2. A backward stepwise (likelihood ratio) method for elimination of variables was used for selection of the final model (SPSS 11.5; SPSS Inc., Chicago, IL, USA). Residuals and values with high leverage were checked to ensure the models assumptions were reasonable.

Seasonal variation in the distribution of the Beautiful Firetail in the forest landscape (i.e. number of sites recorded and relative abundance) was compared using single factor ANOVA.

The distribution of the Beautiful Firetail in Victoria was mapped based on records from the Atlas of Victorian Wildlife (AVW; maintained by the Victorian Department of Sustainability and Environment; accessed 25 February 2003). Existing AVW records (from the year 1800 to 2003) and those from this study were mapped using a geographic information system (ArcView 3.2; ESRI, Redlands, CA, USA).

\section{Results}

An affinity of Beautiful Firetails with coastal habitats is evident from the distribution of AVW records $(n=683)$ for the species in Victoria (Fig. 1). Records are concentrated in the East Gippsland Lowlands and the Gippsland Plains bioregions in the south-east, Wilsons Promontory, the Otways and the Glenelg River area in the south-west (Fig. 1). There are scattered records along the coastal fall of the ranges east of Melbourne and extending into Gippsland. There are only three records of the species inland of the Great Dividing Range: one extreme outlier in the Warby Ranges in north-eastern Victoria; a single record from the
Strathbogie Ranges in central Victoria; and a record from Murrindindi, $70 \mathrm{~km}$ north-east of Melbourne (Fig. 1).

In the present study, the Beautiful Firetail was observed on 117 occasions. The species was detected at $70 \%(n=21)$ of riparian sites (Fig. 2) and at four (13\%) non-riparian sites, all in Bunyip State Park (Fig. 2). It was widely distributed in riparian habitats in Bunyip State Park, occurring at 19 of 20 sites (Fig. 2). The Beautiful Firetail was recorded infrequently at inland sites. It was recorded at two sites along the Acheron River in the Marysville State Forest, east of Narbethong, but was not recorded at comparable sites in Kinglake National Park (Fig. 2).

The results of univariate tests between the occurrence of Beautiful Firetails and the measured habitat variables are shown in Table 1. Sites at which Beautiful Firetails were present had significantly greater sedge cover and density of small trees, and reduced cover of shrubs and fine litter cover (Table 1).

The correlation matrix between the independent habitat variables showed many significant correlations, particularly among ecologically related variables, such as measures of low vegetation and ground cover (e.g. low shrub, fern, sedge, grass, fine litter and bare ground) (Table 2). There was a strong positive correlation between sedge cover and density of small trees and riparian habitats, while increased canopy cover, shrub cover and litter cover were associated with nonriparian habitats (Table 2).

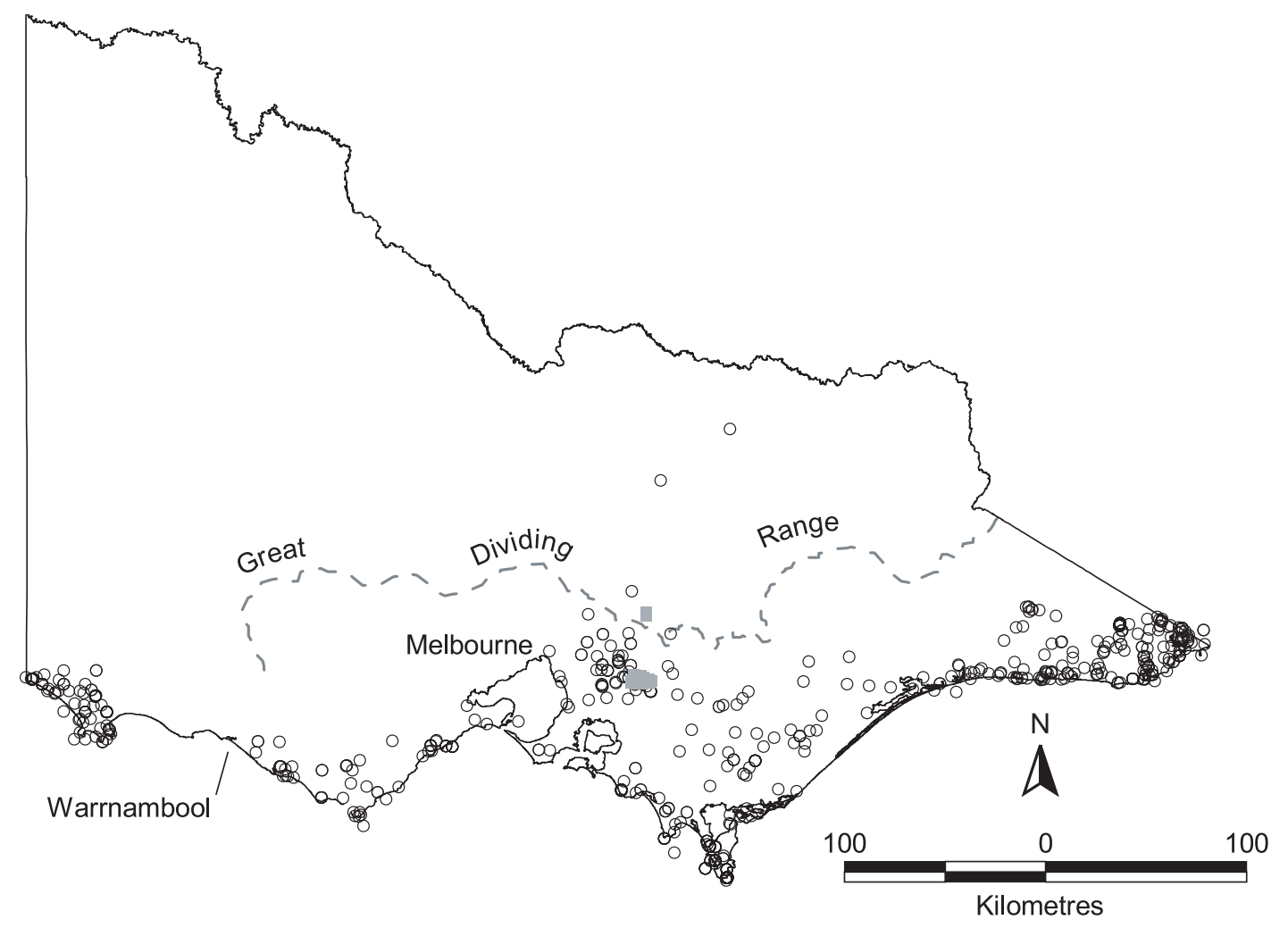

Fig. 1. The distribution of the Beautiful Firetail in Victoria, 1800-2003. Records from the AVW $(\bigcirc)$ and the present study (grey areas) are shown. 